\title{
Transformation from Anatase to Rutile Titania Using Hydrothermal Method: Investigation of Morphology and Thermal Stability
}

\author{
Mpanza P. Ntsikelelo, ${ }^{1}$ Malevu D. Thembinkosi, ${ }^{2}$ Lehloonolo F. Koao, ${ }^{3}$ \\ Motloung V. Setumo, ${ }^{4,5}$ and Motaung E. Tshwafo ${ }^{1 *}$ \\ ${ }^{1}$ Department of Chemistry, University of Zululand (KwaDlangezwa Campus), KwaDlangezwa, \\ Private Bag X1001, KwaDlangezwa 3886, South Africa \\ ${ }^{2}$ School of Chemistry and Physics, Westville Campus, University of KwaZulu-Natal, \\ Private Bag X54001, Durban 4000, South Africa \\ ${ }^{3}$ Department of Physics, University of the Free State (QwaQwa Campus), \\ Private Bag X13, Phuthaditjhaba 9866, South Africa \\ ${ }^{4}$ Department of Physics, Nelson Mandela University, P.O. Box 77000, Port Elizabeth 6031, South Africa \\ ${ }^{5}$ Department of Physics, Sefako Makgatho Health Sciences University, P.O. Box 94, Medunsa 0204, South Africa
}

(Received October 4, 2019; accepted February 14, 2020)

Keywords: titanium dioxide, nanocrystal, annealing temperature, phase transformation

Titanium dioxide nanoparticles were successfully synthesized using the hydrothermal method in an autoclave at $100{ }^{\circ} \mathrm{C}$. The onset of the formation of the rutile phase from 400 to $700{ }^{\circ} \mathrm{C}$ was investigated through the morphology, structure and thermal properties. X-ray diffractometer and Raman spectroscopy confirmed the formation of a hybrid anatase (A) and rutile (B) phase at $400{ }^{\circ} \mathrm{C}$. The nanoparticles formed spherical structures with an average size between 19.799 and $38.685 \mathrm{~nm}$. Thermogravimetric analysis confirmed that a $\mathrm{TiO}_{2}$ nanocrystal subjected to higher temperatures undergoes four degradation stages involving the desorption of water molecules, the loss of organic compounds, and the phase change from amorphous to crystalline anatase.

\section{Introduction}

Titanium dioxide $\left(\mathrm{TiO}_{2}\right)$ has recently attracted considerable attention worldwide owing to its various applications including pigments, dye-sensitized solar cells, photocatalysis, gas sensors, and optoelectronics. ${ }^{(1-8)}$ Among the applications, much interest has been focused on photocatalysis where $\mathrm{TiO}_{2}$ is an important photocatalytic material because of its ability to decompose organic pollutants. ${ }^{(9)}$ It has a number of advantages including nontoxicity, a low cost, and strong oxidation and reduction abilities under solar light. ${ }^{(10,11)}$ It naturally exists in the phases of tetragonal anatase, tetragonal rutile, and orthorhombic brookite with energy band gaps of 3.23, 3.05, and $3.26 \mathrm{eV}$, respectively. Amongst these three phases, rutile is the most stable phase. ${ }^{(10)}$ Furthermore, rutile has high charge carrier recombination, which extends the photocatalytic activity of the $\mathrm{TiO}_{2}$ visible light region. ${ }^{(10)}$

*Corresponding author: e-mail: motaungte@live.com https://doi.org/10.18494/SAM.2020.2649 
According to the literature, a number of synthesis methods are employed to synthesize $\mathrm{TiO}_{2}$ nanomaterials. Some of the commonly applied methods include the sol-gel, ${ }^{(12,20,21)}$ chemical vapor deposition, ${ }^{(22,23)}$ solvothermal, ${ }^{(24)}$ and hydrothermal ${ }^{(25)}$ methods. These methods require a high-energy vacuum and a high temperature, and for the most part include complex procedures. Some of these methods are also destructive and include dangerous gases. Furthermore, previous studies have shown that it is difficult to obtain a hybrid anatase and rutile phase. The hydrothermal method is a promising technique for the synthesis of mixed anataserutile (A-R) $\mathrm{TiO}_{2}$ nanocrystals because of its mild preparation conditions and low cost. It also has the advantage in that the temperature gradient can be controlled and maintained, making it easy to crystallize a material. In addition, previous studies have shown that the physical properties of $\mathrm{TiO}_{2}$, such as the surface area, crystallite form, crystallite size, morphology, and dispersion, can be well controlled via hydrothermal processing parameters. ${ }^{(26,27)}$ Selman and Husham $^{(28)}$ reported the presence of both phases when as-prepared samples were annealed at $550{ }^{\circ} \mathrm{C}$. Similar results were obtained in Refs. 29 and 30, which suggests that an A-R mixture exists at $450{ }^{\circ} \mathrm{C}$ and that anatase fully transforms to the rutile phase at temperatures of $800{ }^{\circ} \mathrm{C}$ and above.

More information is required about the synthesis of the hybrid of the two phases of $\mathrm{TiO}_{2}$ and the transformation to the rutile phase. In the present study, we synthesized a hybrid of the anatase and rutile phases, and clarified the systematic transformation to the rutile phase as a function of temperature. X-ray diffractometry (XRD), Raman spectroscopy, transmission electron microscopy (TEM), and thermaogravimetric analysis (TGA) were used to characterize the samples.

\section{Experimental Procedure}

\subsection{Sample preparation}

All the chemicals used during the synthesis were purchased from Sigma-Aldrich. The gel was prepared by mixing $45 \mathrm{ml}$ of deionized water with $15 \mathrm{ml}$ of $\mathrm{HCl}$ under constant stirring for $5 \mathrm{~min}$ in a fume hood. $2 \mathrm{ml}$ of titanium (IV) isopropoxide was added to the solution under constant stirring for $10 \mathrm{~min}$. The mixture was transferred to a preheated autoclave oven at 100 ${ }^{\circ} \mathrm{C}$ for $2 \mathrm{~h}$ and then allowed to cool to room temperature before centrifugation. The collected white particles were washed several times using deionized water. The as-prepared $\mathrm{TiO}_{2}$ nanocrystalline powders were then annealed at temperatures of $400,500,600$, and $700{ }^{\circ} \mathrm{C}$ for $1 \mathrm{~h}$.

\subsection{Characterization}

The crystal structure and phase composition of the crystalline $\mathrm{TiO}_{2}$ nanopowders were characterized by XRD (Bruker-AXS D8) with a $2 \theta$ diffraction angle in the range of 20 to $80^{\circ}$ $(\mathrm{CuK} \alpha=1.5418 \AA$ with $40 \mathrm{kV} / 4 \mathrm{~mA}$ radiation). Low-frequency, vibrational, and rotational modes were determined by Raman spectroscopy (Horiba Jobin Yvon T64000) with an excitation wavelength $(\lambda)$ of $514 \mathrm{~nm}$ at a low power $(12 \mathrm{mV})$ to minimize unwanted sample heating 
effects. TEM (JEOL 1010) and high-resolution TEM (HRTEM, JEOL JEM-2100) were used to examine the average particle size and selected-area electron diffraction (SAED) pattern of the nanocrystalline $\mathrm{TiO}_{2}$, respectively. Before TEM analyses, $\mathrm{TiO}_{2}$ nanoparticles were uniformly dispersed in ethanol using a sonicator for $30 \mathrm{~min}$. This was followed by drop-casting onto a carbon-coated copper grid and drying at room temperature (RT) before loading in the chamber. Fourier transform infrared spectrometry (FTIR) was used to obtain infrared absorption spectra of the nanocrystalline $\mathrm{TiO}_{2}$ powders. A Perkin Elmer Pyris 6 thermogravimetric analyzer (TGA) was used to obtain the decomposition mechanisms for samples subjected to different temperatures. The analysis was carried out at a heating rate of $10{ }^{\circ} \mathrm{C} \mathrm{min}-1$ from 30 to $700{ }^{\circ} \mathrm{C}$ under inert gas (nitrogen) in a perforated aluminum pan that was closed.

\section{Results and Discussion}

\subsection{Structural analysis}

Figure 1 shows the XRD patterns of the nanocrystalline $\mathrm{TiO}_{2}$ powders obtained at different annealing temperatures. All powder samples are polycrystalline with a tetragonal crystal structure belonging to the I41/amd space group (No. 141) with lattice parameters $a=3.7845 \AA$ and $c=9.5143 \AA$. The most intense diffraction peaks for both $\mathrm{A}(101)$ and $\mathrm{R}(110)$ were then used to estimate the crystallite size $(D)$ of the prepared samples by using the Scherrer equation ${ }^{(34)}$

$$
D=\frac{k \lambda}{\beta \cos \theta},
$$

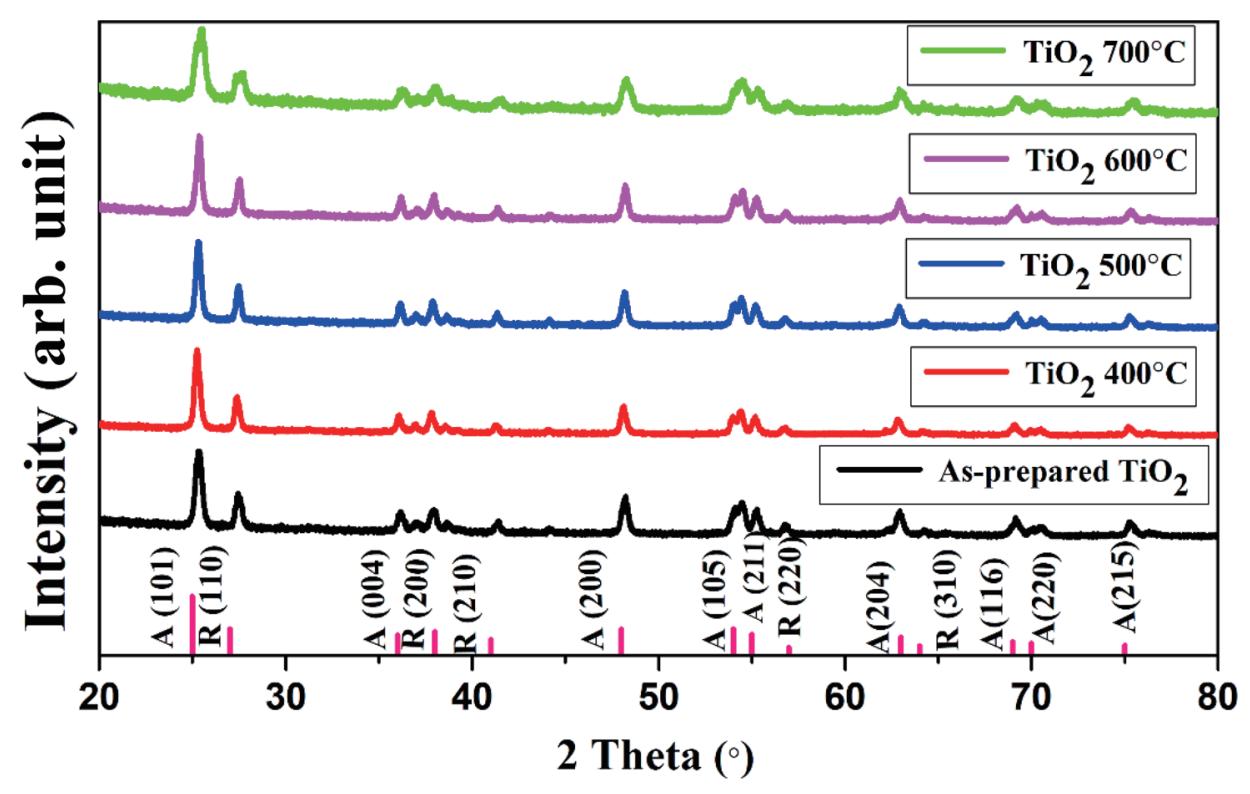

Fig. 1. (Color online) XRD patterns of hydrothermally synthesized $\mathrm{TiO}_{2}$ showing the patterns of as-prepared $\mathrm{TiO}_{2}$ nanocrystals and $\mathrm{TiO}_{2}$ nanocrystals annealed at temperatures of $400,500,600$, and $700{ }^{\circ} \mathrm{C}$. 
where $\beta$ is the full width at half maximum wavelength (FWHM) at $2 \theta$ angle (in radians), $k$ is the Scherrer constant, which is $0.9, \lambda$ is the $\mathrm{X}$-ray radiation wavelength with $\mathrm{Cu}-\mathrm{K} \alpha$, and $\theta$ is the diffraction angle in radians. The estimated values are summarized in Table 1.

All the patterns of the $\mathrm{TiO}_{2}$ nanocrystals were obtained in the diffraction angle range of $2 \theta$ $=20-80^{\circ}$. The diffraction peaks for the anatase (A) phase appear at the following $2 \theta$ angles with the corresponding planes given in parentheses: 25.62 (101), 38.48 (004), 54.51 (105), 55.39 (211), $62.99^{\circ}(204), 69.30^{\circ}(116), 70.49^{\circ}(220)$, and $75.47^{\circ}$ (215). On the other hand, the rutile (R) phase peaks appears at $2 \theta$ angles of $27.82^{\circ}(110), 36.49^{\circ}(200), 41.67^{\circ}$ (210), and $64.30^{\circ}(310)$. Both phases correspond to the tetragonal crystal structure matching JCPDS (21-1276). Figure 2 shows that the enlarged A (101) and R (100) peaks shifted slightly to the left with increasing annealing temperature. The peak shift implies that there were changes in lattice parameters, which is a good indication of phase transformation. ${ }^{(31)}$

Table 1

Summary of the sample identification, FWHM, crystallite size, lattice parameters, dislocation density, and microstrain of the prepared $\mathrm{TiO}_{2}$ powders.

\begin{tabular}{|c|c|c|c|c|c|c|c|}
\hline Temperature $\left({ }^{\circ} \mathrm{C}\right)$ & $\begin{array}{l}\text { Phase (hkl) and } \\
2 \theta \text { position (deg) }\end{array}$ & $\begin{array}{c}\text { FWHM } \\
\text { (deg) }\end{array}$ & $\begin{array}{l}\text { Crystallite size } \\
\text { (nm) }\end{array}$ & $a(\AA)$ & $c(\AA)$ & $\delta 10^{14} \mathrm{lin} / \mathrm{m}^{2}$ & $\varepsilon 10^{4} \operatorname{lin}^{-2} \mathrm{~m}^{-4}$ \\
\hline \multirow{2}{*}{ As-prep } & A:101 (25.270) & 0.391 & $15.70( \pm 0.356)$ & 3.814 & 9.623 & 0.004 & 0.095 \\
\hline & $\mathrm{R}: 110$ (27.820) & 0.960 & $8.91( \pm 0.087)$ & 4.601 & 2.843 & 0.013 & 0.233 \\
\hline \multirow{2}{*}{400} & A:101 (25.180) & 0.356 & $23.91( \pm 0.238)$ & 3.742 & 9.521 & 0.002 & 0.087 \\
\hline & $\mathrm{R}: 110(27.741)$ & 0.397 & $21.56( \pm 0.224)$ & 4.710 & 2.426 & 0.002 & 0.096 \\
\hline \multirow{2}{*}{500} & A:101 (25.273) & 0.282 & $30.14( \pm 0.293)$ & 3.763 & 9.373 & 0.001 & 0.069 \\
\hline & R:110 (27.660) & 0.258 & $33.20( \pm 0.303)$ & 4.721 & 2.445 & 0.001 & 0.063 \\
\hline \multirow{2}{*}{600} & A:101 (25.275) & 0.275 & $31.01( \pm 0.336)$ & 3.725 & 9.355 & 0.001 & 0.067 \\
\hline & $\mathrm{R}: 110(27.728)$ & 0.242 & $35.34( \pm 0.348)$ & 4.712 & 2.429 & 0.001 & 0.059 \\
\hline \multirow{2}{*}{700} & A:101 (25.374) & 0.267 & $31.90( \pm 0.298)$ & 3.723 & 9.346 & 0.001 & 0.065 \\
\hline & $\mathrm{R}: 110$ (27.763) & 0.219 & $39.02( \pm 0.394)$ & 4.707 & 2.421 & 0.001 & 0.053 \\
\hline
\end{tabular}

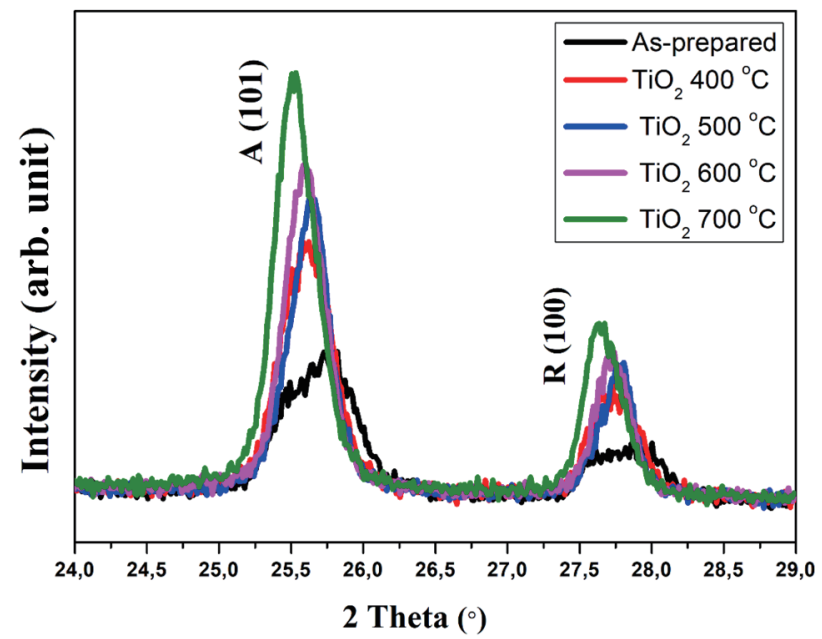

Fig. 2. (Color online) Enlarged XRD patterns showing shift of anatase A (101) and rutile R (100) $\mathrm{TiO}_{2}$ peaks due to annealing. 
It is evident from the figure that when the $\mathrm{TiO}_{2}$ powder was heated to $400{ }^{\circ} \mathrm{C}$ and above, the major peaks for the anatase and rutile phases were observed at $2 \theta=25.3$ and $27.5^{\circ}$ for the (101) and (110) planes respectively. In fact, they became more pronounced with increasing annealing temperature, which is known to indicate improved crystallinity. ${ }^{(20)}$ The crystallinity indices shown in Table 1 suggest that a mixed phase of $\mathrm{A}-\mathrm{R} \mathrm{TiO}_{2}$ was achieved during the synthesis that consisted of about $64.3 \% \mathrm{~A}$ and $35.7 \% \mathrm{R}$. The values fall within the range of values in the literature..$^{(31-33)}$ Nonetheless, in this study, the rutile transformation appeared to be rapid even though complete crystallization did not occur at $700{ }^{\circ} \mathrm{C}$. However, Zhou et al. ${ }^{(33)}$ argued that the A-R phase transformation is slow between 400 and $800{ }^{\circ} \mathrm{C}$ and that a complete rutile transformation should be observable at a temperature of about $1000{ }^{\circ} \mathrm{C}$.

The calculated crystallite sizes for anatase and rutile ranged from 15.70 to $31.90 \mathrm{~nm}$ and from $8.91 \mathrm{~nm}$ to $39.02 \mathrm{~nm}$, respectively. From the analysis results, the peak intensity of anatase appears to increase, while the FWHM decreases with increasing annealing temperature. This implies an increase in crystallite size and decreases in microstrain and dislocation density, thus improving the crystalline structure. The calculated microstrain and dislocation density were obtained using Eqs. (2) and (3), respectively.

$$
\begin{gathered}
\delta=\frac{1}{D^{2}} \\
\varepsilon=\frac{\beta \cos \theta}{4}
\end{gathered}
$$

Equations (2) and (3) ${ }^{(34)}$ provide the minimum values for the probability of the microstrain and dislocation density of samples, respectively. The crystallinity of nanocrystalline $\mathrm{TiO}_{2}$ improves if there is a lower dislocation density and less microstrain. Additionally, increasing the temperature affects the structural properties of the nanoparticles.

Table 1 also shows that as the annealing temperature increases, the lattice parameters $a$ and $c$ decrease owing to a slow phase transformation and the rate of coarsening of the particles and/or surface energies and the rate of packing of particles increase. Li et al. ${ }^{(35)}$ demonstrated that slight decreases in lattice parameters suggest a phase transformation as the anatase lattice is being compressed during postannealing. This means that during annealing, the A-R phase undergoes tensile and compression strain, which results in lattice imperfections. The weight intensity ratio $\left(W_{R}\right)$ of the $\mathrm{A}-\mathrm{R}$ phase as a function of annealing temperature was calculated by relating the XRD integrated intensities using the Spurr equation. ${ }^{(36)}$

$$
W_{R}=\frac{I_{R(100)}}{0.884 I_{A(101)}+I_{R(100)}},
$$

where $W_{R}$ is the weight fraction of rutile in the sample, and $I_{A(101)}$ and $I_{R(100)}$ are the integrated main peak intensities of anatase and rutile, respectively. The correction factor of 0.884 was 
calculated using known mixtures of pure, finely crystalline anatase, and rutile. ${ }^{(36)}$ Figure 3 shows the A-R weight percentage (\%) as a function of annealing temperature and the results show linear increases and decreases in $\mathrm{R}$ and $\mathrm{A}$ with increasing annealing temperature.

We propose that there might be a direct transformation from the A phase to the $\mathrm{R}$ phase, which is evident from RT. Khatun et al. ${ }^{(37)}$ obtained similar results, although they incorporated some dopants to promote the A-R transformation at RT. Choi et al. ${ }^{(38)}$ also obtained comparable results by evaluating the A-R transformation at $\mathrm{RT}$ after doping $\mathrm{TiO}_{2}$. Therefore, a direct $\mathrm{A}-\mathrm{R}$ transformation can be easily achieved at RT if a number of factors, including the preparation method and dopants are satisfied. Many researchers ${ }^{(36,39)}$ have observed similar types of transformation from the A phase to the $\mathrm{R}$ phase, although the transition was observed between 700 and $1300{ }^{\circ} \mathrm{C}$. The results of this study suggest that the transformation occurs and the content of rutile starts to dominate between 400 and $700{ }^{\circ} \mathrm{C}$.

\subsection{Raman analysis}

Raman spectra of the as-synthesized and annealed samples are presented in Fig. 4. It is known that the vibrational spectrum of anatase $\mathrm{TiO}_{2}$ consists of six Raman active modes and that the major bands of the anatase phase are observed at 144, 197, 399, 513, 519 and $639 \mathrm{~cm}^{-1}$, which are attributed to the symmetries of Eg, Eg, Blg, A1g, Blg, and Eg, respectively. ${ }^{(40)}$ The rutile phase vibrational spectrum has four Raman active modes or major bands that are shown at $145,240,445$, and $610 \mathrm{~cm}^{-1}$, which correspond to the symmetries attributed to B1g, the twophoton scattering or second-order effect, $\mathrm{Eg}$, and $\mathrm{Alg}$, respectively. ${ }^{(41)}$

Raman bands of the nanocrystalline $\mathrm{TiO}_{2}$ are observed at $142.50 \mathrm{~cm}^{-1}(\mathrm{Eg}), 194.95 \mathrm{~cm}^{-1}$ (Eg), $396.04 \mathrm{~cm}^{-1}(\mathrm{~B} 1 \mathrm{~g}), 514.94 \mathrm{~cm}^{-1}(\mathrm{~A} 1 \mathrm{~g})$, and $638.25 \mathrm{~cm}^{-1}(\mathrm{Eg})$ for the $\mathrm{TiO}_{2}$ sample annealed at $400{ }^{\circ} \mathrm{C}$. The most intense peak is observed at $142.50 \mathrm{~cm}^{-1}(\mathrm{Eg})$ and is attributed to the interactions of $\mathrm{Ti}-\mathrm{Ti}$, which are covalent in nature. An increase in annealing temperature to $500{ }^{\circ} \mathrm{C}$ seems to promote the initiation of phase transformation to rutile. In addition, a high

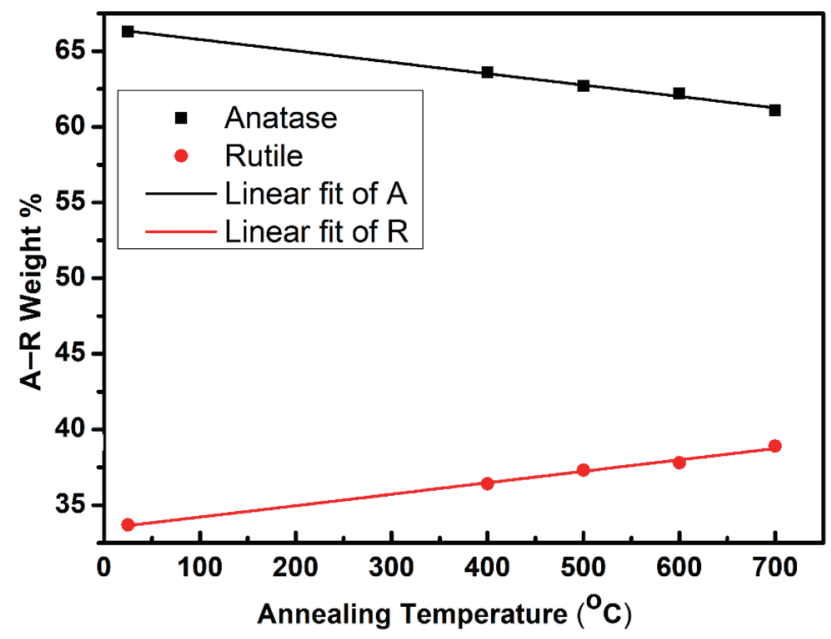

Fig. 3. (Color online) A-R weight percentage (\%) in the samples annealed at various temperatures. 


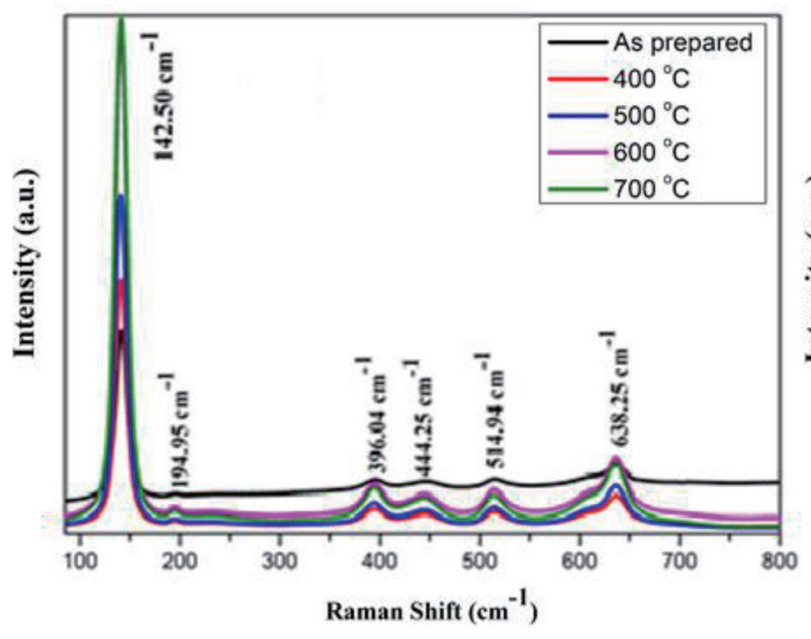

(a)

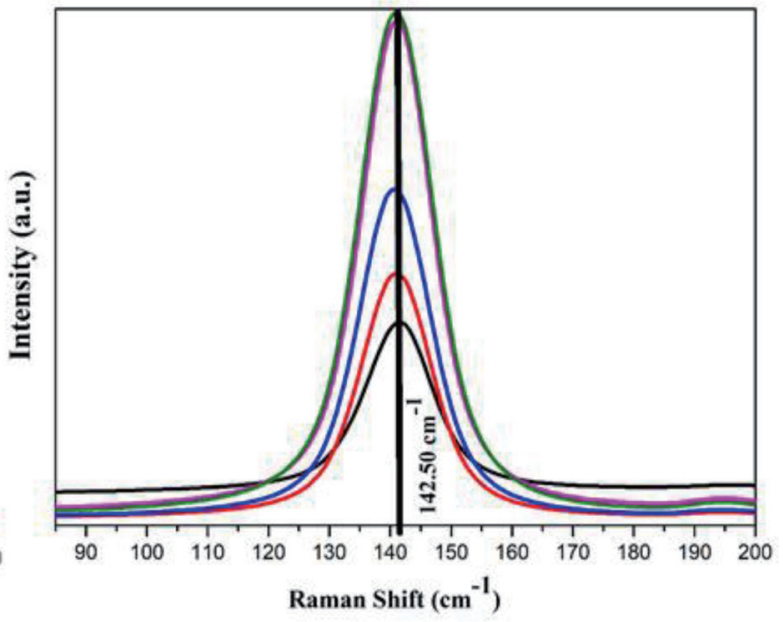

(b)

Fig. 4. (Color online) (a) Full Raman spectra and (b) zoomed part of the spectra of the nanocrystalline $\mathrm{TiO}_{2}$ powders (as-prepared and annealed at various temperatures).

annealing temperature of $700{ }^{\circ} \mathrm{C}$ exhibits more intense and sharper crystalline A-R peaks, indicating an increase in crystallinity that is consistent with the XRD patterns. In fact, an increase in crystallite size with temperature is in line with the sharper peaks observed at the highest temperature. The electron-phonon interaction caused by the increase in particle size as confirmed by literature could also be accountable for the observation in this study. ${ }^{(36)}$

\section{Morphological Analysis}

\subsection{TEM studies}

The TEM analysis was carried out to determine the growth orientation and crystallite distribution, and to confirm the average crystallite size distribution. Figure 5 shows TEM images of (a) as-prepared nanocrystals and samples annealed at temperatures of (b) 400, (c) 500, (d) 600 , and (e) $700{ }^{\circ} \mathrm{C}$. The nanocrystals are well distributed with average particle sizes of (a) $19.799 \pm 2.030$, (b) $24.976 \pm 1.953$, (c) $30.206 \pm 4.694$, (d) $31.690 \pm 2.513$, and (e) $38.685 \pm 2.905$ $\mathrm{nm}$. The results suggest that the average particle size increased with the annealing temperature and formed uniform spherical structures. This confirmed the results of XRD and suggests that the material could be an ideal photocatalyst for accelerating the photodegradation of polymers. ${ }^{(42)}$

\subsection{SAED analysis}

Figure 6 shows SAED patterns of the (a) as-prepared $\mathrm{TiO}_{2}$ and samples annealed at temperatures of (b) 400 , (c) 500 , (d) 600 , and (e) $700{ }^{\circ} \mathrm{C}$, which correspond to both the $\mathrm{A}$ and $\mathrm{R}$ phases of $\mathrm{TiO}_{2}$. 

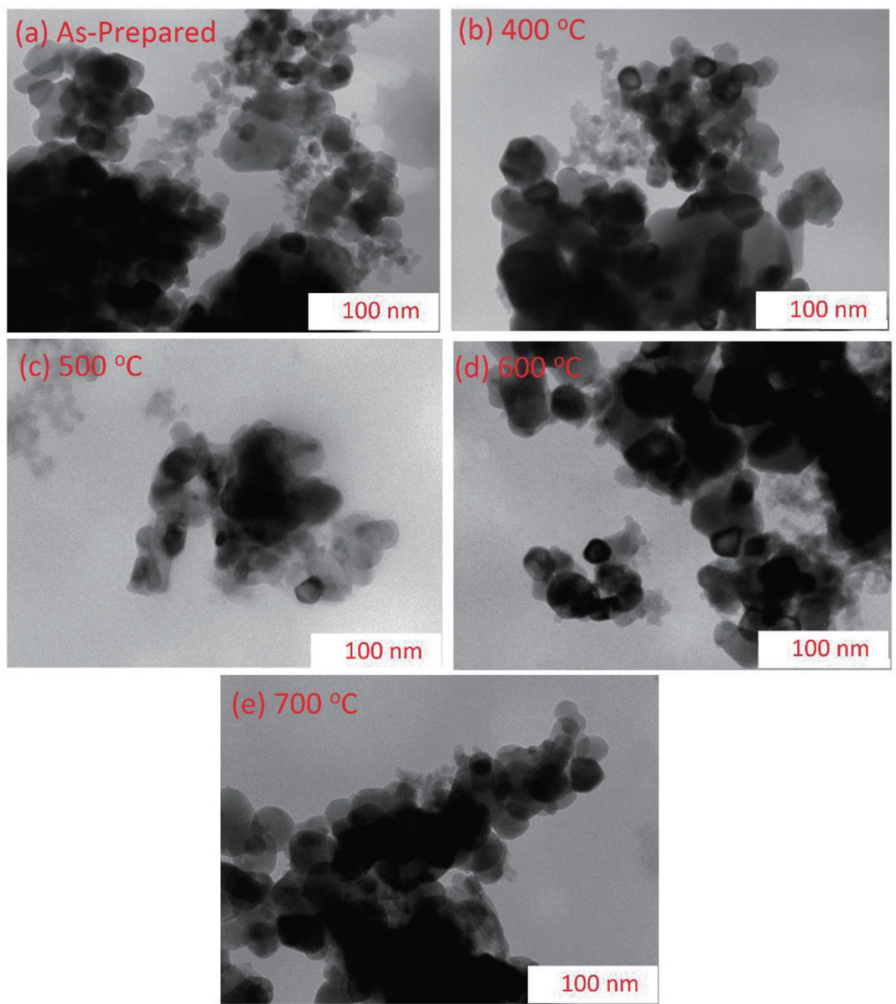

Fig. 5. (Color online) TEM images of the hydrothermally synthesized nanocrystalline $\mathrm{TiO}_{2}$ powders: (a) asprepared and annealed at (b) 400 , (c) 500 , (d) 600 , and (e) $700{ }^{\circ} \mathrm{C}$.

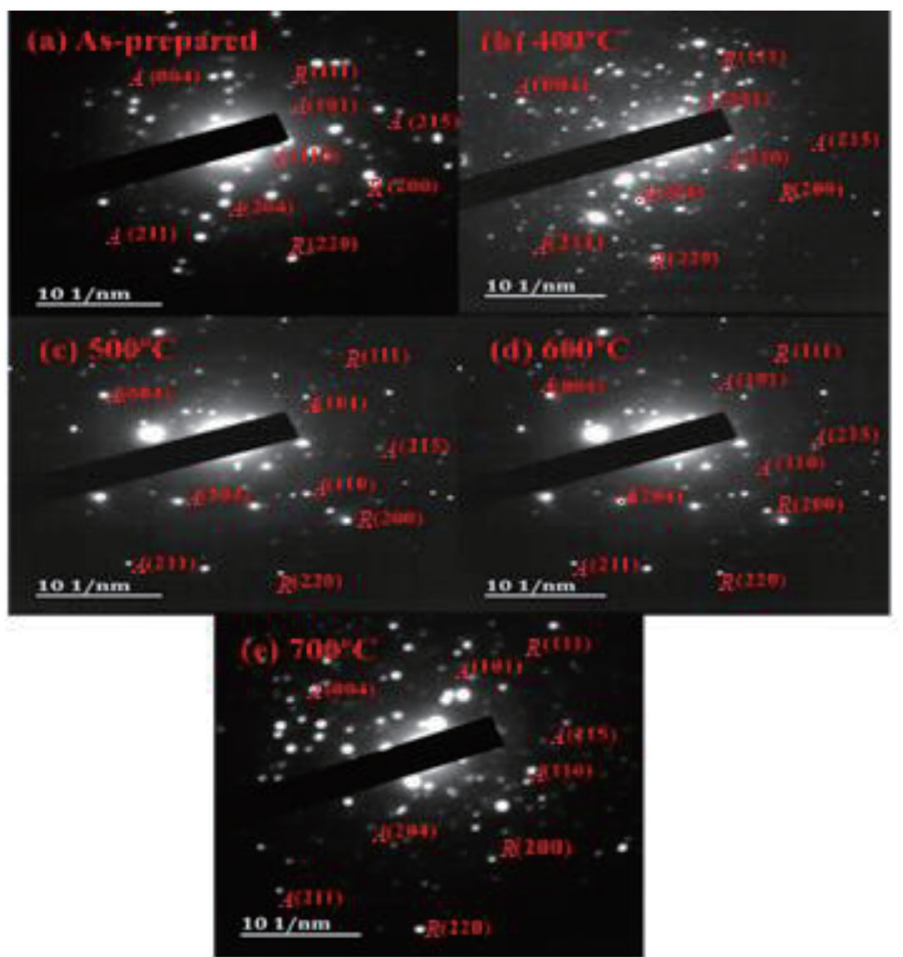

Fig. 6. (Color online) SAED patterns of the hydrothermally synthesized nanocrystalline $\mathrm{TiO}_{2}$ powders: (a) asprepared $\mathrm{TiO}_{2}$, and samples annealed at (b) 400 , (c) 500 , (d) 600 , and (e) $700{ }^{\circ} \mathrm{C}$. 
The intensity of the diffraction rings clearly shows the crystallites of crystalline particles. The spot brightness increases with the annealing temperature; thus, improving the crystallinity of $\mathrm{TiO}_{2}$ samples is considered to be important for improving the mechanical properties of polymers. ${ }^{(43)}$ The A and $\mathrm{R}$ diffraction peaks were determined using the $\mathrm{d}$-spacing corresponding to each ring of the SAED pattern. The orderly allocation of the ring d-spacing measurements is attributed to the (101), (103), (004), (200), (105), (211), (204), (116), (220), and (215) planes for the A phase of $\mathrm{TiO}_{2}$, whereas the R phase of $\mathrm{TiO}_{2}$ occurs at the (200), (111), (210), (220), and (310) planes, which is consistent with the XRD, TEM, and Raman results.

\subsection{FTIR analysis}

Figure 7 shows the FTIR spectra of the as-prepared $\mathrm{TiO}_{2}$ nanocrystalline powder and the powders annealed at various temperatures of $400,500,600$, and $700{ }^{\circ} \mathrm{C}$. The spectra were recorded in the $300-4000 \mathrm{~cm}^{-1}$ wavelength range.

The slight dips at around $3650-3200 \mathrm{~cm}^{-1}$ are attributed to the $\mathrm{O}-\mathrm{H}$ group vibration modes due to the bending and stretching of the hydroxyl group and water adsorption on the surface. The $1753.48 \mathrm{~cm}^{-1}$ band is attributed to the Ti-OH vibration mode or carbonyl group. The observed band with absorption around 1354 and $1368(1400) \mathrm{cm}^{-1}$ is assigned to the Ti-O-Ti group vibration $\left(\mathrm{CH}_{2}\right)$ and indicates the presence of the $\mathrm{TiO}_{2}$ anatase phase. ${ }^{(44)}$ The observed band around $1108 \mathrm{~cm}^{-1}$ is attributed to a characteristic peak of rutile having a Ti-O-Ti bond. ${ }^{(45)}$ Furthermore, the band region at around $400 \mathrm{~cm}^{-1}$ is attributed to the peak absorption of $\mathrm{TiO}_{2}$ having an $\mathrm{O}-\mathrm{Ti}-\mathrm{O}$ bond, which indicates an anatase phase $\mathrm{TiO}_{2}$ mode that is transverse. As the annealing temperature increases, the Ti-O-Ti band around $1103 \mathrm{~cm}^{-1}$ becomes broad and the intensity increases, which can be attributed to the increase in the crystallinity of rutile as indicated by the XRD, Raman, SAED, and TEM results. This further indicates that the number of Ti-O-Ti vibrations also increases with the annealing temperature. ${ }^{(46)}$

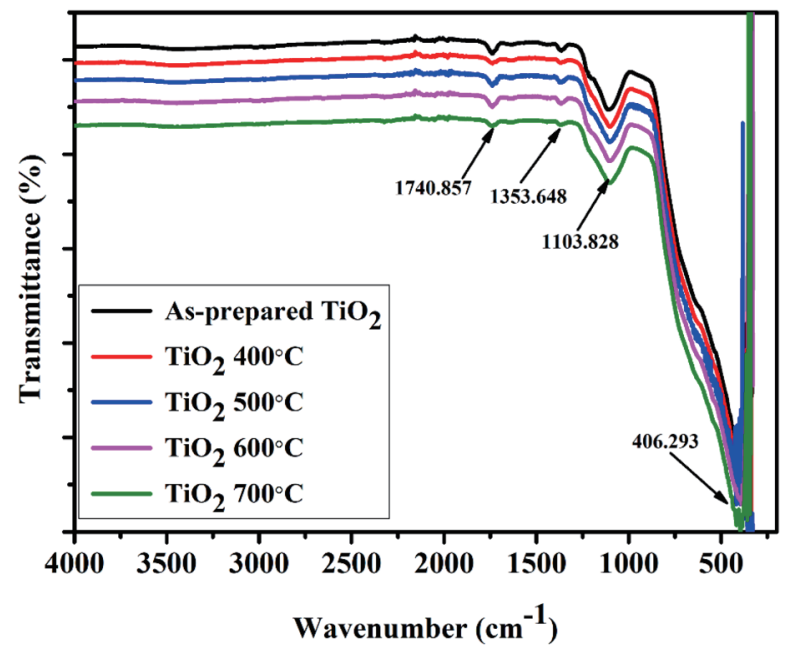

Fig. 7. (Color online) FTIR spectra of the hydrothermally synthesized nanocrystalline $\mathrm{TiO}_{2}$ powders: as-prepared and annealed at various temperatures of $400,500,600$, and $700{ }^{\circ} \mathrm{C}$. 


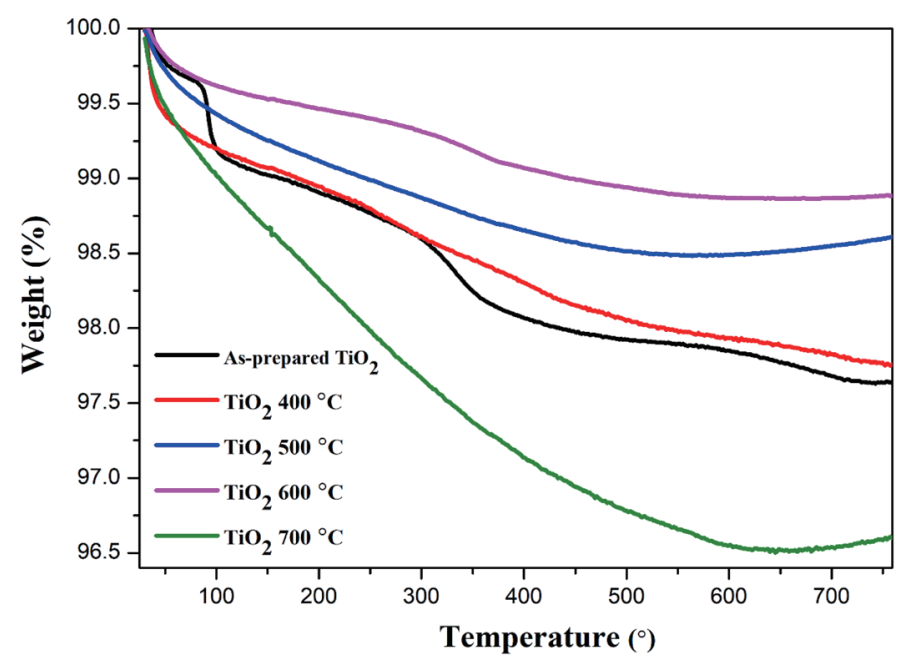

Fig. 8. (Color online) TGA curves of the hydrothermally synthesized nanocrystalline $\mathrm{TiO}_{2}$ powders subjected to different annealing temperatures.

\section{Thermal Analysis}

\subsection{Thermogravimetric analysis}

Figure 8 shows the results of TGA analysis carried out to determine the mass loss versus temperature behavior of the nanocrystalline $\mathrm{TiO}_{2}$ powders. The results suggest that the weight loss of nanocrystal $\mathrm{TiO}_{2}$ occurs in different stages in the temperature ranges of around 31-114, $114-413,413-600$, and $600-700{ }^{\circ} \mathrm{C}$. The first weight loss occurs at $31-114{ }^{\circ} \mathrm{C}$, which is due to the desorption of water absorbed at the surfaces of the $\mathrm{TiO}_{2}$ molecules. This is in agreement with FT-IR studies, which showed the presence of water molecules in the $3650-1753.48 \mathrm{~cm}^{-1}$ region. The temperature range of $11-413{ }^{\circ} \mathrm{C}$ corresponds to the second weight loss, which is considered to be the loss of organic compounds known to contain oxygen and carbon. ${ }^{(47)}$ The third weight loss in the temperature range of $413-600{ }^{\circ} \mathrm{C}$ is attributed to the transformation from the amorphous anatase phase to a hybrid crystalline phase and the onset of rutile. ${ }^{(48)}$ However, in this study, the formation of rutile seems to gain momentum at 600 to $700{ }^{\circ} \mathrm{C}$ and above as confirmed by the results of XRD and Raman spectroscopy. For the samples annealed at temperatures above $400{ }^{\circ} \mathrm{C}$, the slight mass decrease from 100 to $300{ }^{\circ} \mathrm{C}$ can be attributed to the gradual crystallization or slow phase transformation of the material, eventually with water loss due to the high temperature.

\section{Conclusion}

In this study, mixed $\mathrm{A}-\mathrm{R} \mathrm{TiO}_{2}$ nanocrystals were successfully synthesized using the hydrothermal method. The effects of the annealing temperature on the structure, morphology and thermal stability of the mixed nanocrystal were investigated by XRD, Raman spectroscopy, 
TEM, FTIR, and TGA. XRD confirmed the presence of both the anatase and rutile phases synthesized at RT. All the major vibrational modes identified by Raman spectroscopy were in agreement with the results of XRD analysis. The spherical nanoparticles with average particle sizes between 19.799 and $38.685 \mathrm{~nm}$ were observed by TEM. SAED confirmed the presence of well-defined $\mathrm{TiO}_{2}$ nanocrystals. FTIR confirmed the presence of the functional groups and the structural change that $\mathrm{TiO}_{2}$ undergoes as the nanocrystals are subjected to postannealing. From the results of TGA analysis, we verified the existence of four mass losses of the $\mathrm{TiO}_{2}$ nanocrystals at $31-114,114-413,413-600$, and $600-700{ }^{\circ} \mathrm{C}$.

\section{Conflict of Interest}

The authors declare that they have no conflict of interest regarding the publication of this paper.

\section{Acknowledgments}

It would not have been possible to carry out this research without the UCDP financial support from University of KwaZulu-Natal.

\section{References}

1 A. Al-Kattan, A. Wichser, R. Vonbank, S, Brunner, A. Ulrich, S, Zuin, and B. Nowack: Environ. Sci. Process Impacts 15 (2013) 2186. https://doi.org/10.1039/C3EM00331K

2 J. N. Hart, D. Menzies, Y. B. Cheng, G. P. Simon, and L. Spiccia: J. Sol-Gel Sci. Technol. 40 (2006) 45. https:// doi.org/10.1007/s10971-006-8387-6

3 Y. H. Xu, H. R. Chen, Z. X. Zeng, and B. Lei: Appl. Surf. Sci. 252 (2006) 8565. https://doi.org/10.1016/ j.apsusc.2005.11.072

4 K. Nakata and A. Fujishima: J. Photochem. Photobiol., C 13 (2012) 169. https://doi.org/10.1016/ j.jphotochemrev.2012.06.001

5 I. Sta, M. Jlassi, M. Hajji, M. F. Boujmil, R. Jerbi, M. Kandyla, M. Kompitsas, and H. Ezzaouia: J. Sol-Gel Sci. Technol. 72 (2014) 421. https://doi.org/10.1007/s10971-014-3452-z

6 W. C. Tian, Y. H. Ho, C. H. Chen, and C. Y. Kuo: Sensors 13 (2013) 865. https://doi.org/10.3390/s130100865

7 Y. Liu, R. Che, G. Chen, J. Fan, Z. Sun, Z. Wu, M. Wang, B. Li, J. Wei, Y. Wei, G. Wang, G. Guan, A. A. Elzatahry, A. A. Bagabas, A. M. Al-Enizi, Y. Deng, H. Peng, and D. Zhao: Sci. Adv. 1 (2015) 1500166. https:// doi.org/10.1126/sciadv. 1500166

8 J. T. Carneiro, T. J. Savenije, J. A. Moulijn, and G. Mul: J. Phys. Chem. C. 115 (2011) 2211. https://doi. org/10.1021/jp110190a

9 H. Dong, G. Zeng, L. Tang, C. Fan, C. Zhang, X. He, and Y. He: Water Res. 79 (2015) 128. https://doi. org/10.1016/j.watres.2015.04.038

10 V. C. Fuertes, C. F. Negre, M. B. Oviedo, F. P. Bonafé, F. Y. Oliva, and C. G. Sánchez: J. Phys.: Condens. Mater., A. 25 (2013) 115304.

11 N. Feng, Q. Wang, A. Zheng, Z. Zhang, J. Fan, S. B. Liu, J. P. Amoureux, and F. Deng: J. Am. Chem. Soc. 135 (2013) 1607. https://doi.org/10.1021/ja312205c

12 D. A. Hanaor and C. C. Sorrell: J. Mater. Sci. 46 (2011) 855. https://doi.org/10.1007/s10853-010-5113-0

13 T. Arlt, M. Bermejo, M. A. Blanco, L. Gerward, J. Z. Jiang, J. S. Olsen, and J. M. Recio: Phys. Rev. 61 (2000) 14414. https://doi.org/10.1103/PhysRevB.61.14414

14 S. S. Pradhan, S. K. Pradhan, V. Bhavanasi, S. Sahoo, S. N. Sarangi, S. Anwar, P. K. Barhai, and S. S. Pradhan: Thin Solid Films 520 (2012) 1809. https://doi.org/10.1016/j.tsf.2011.08.106

15 A. Ali, S. Zareen, and M. Irfan: Eur. Sci. J. 2 (2014) 447.

16 W. Wang, B. Gu, L. Liang, W. A. Hamilton, and D. J. Wesolowski: J. Phys. Chem. B 108 (2004) 14789. https:// doi.org/10.1021/jp0470952 
17 M. Šćepanović, B. Abramović, A. Golubović, S. Kler, M. Grujić-Brojčin, Z. Dohčević-Mitrović, B. Babić, B. Matović, and Z.V. Popović: J. Sol-Gel Sci. Technol. 61 (2012) 390. https://doi.org/10.1007/s10971-011-2639-9

18 Y. F. Li and Z. P. Liu: J. Am. Chem. Soc. 133 (2011) 15743. https://doi.org/10.1021/ja206153v

19 M. D’Arienzo, J. Carbajo, A. Bahamonde, M. Crippa, S. Polizzi, R. Scotti, L. Wahba, and F. Morazzoni: J. Am. Chem. Soc. 133 (2011) 17652. https://doi.org/10.1021/ja204838s

20 K. D. Ángel-Sanchez, O. V. Cuchillo, A. A. Elguezabal, A. Cruz-López, and A. Herrera-Gómez: Mater. Chem. Phys. 139 (2013) 423. https://doi.org/10.1016/j.matchemphys.2013.01.009

21 C. Albano, Y. Sarmiento, and G. González: Weinheim: Macromol. Symp. 321 (2012) 76. https://doi. org/10.1002/masy.201251112

22 I. Djerdj, A. M. Tonejc, M. Bijelić, V. Vranes, and A. Turković: Vacuum 80 (2005) 371. https://doi.org/10.1016/ j.vacuum.2005.06.015

23 M. M. Byranvand, A. N. Kharat, L. Fatholahi, and Z. M. Beiranvand: J. Nanostruct. 3 (2013) 1. https://doi. org/10.7508/JNS.2013.01.001

24 H. Luo, L. Shen, K. Rui, H. Li, and X. Zhang, X: J. Alloys Compd. 572 (2013) 37. https://doi.org/10.1016/ j.jallcom.2013.03.247

25 B. Xue, T. Sun, F. Mao, L. C. Sun, W. Yang, Z.D. Xu, and X. Zhang: Mater. Res. Bull. 46 (2011) 1524. https:// doi.org/10.1016/j.materresbull.2011.05.019

26 M. Akarsu, M. Asiltürk, F. Sayilkan, N. Kiraz, E. Arpaç, and H. Sayilkan: Turk. J. Chem. 30 (2006) 333

27 X. Chen and S. S. Mao: Chem. Rev. 107 (2007) 2891. https://doi.org/10.1021/cr0500535

28 A. M. Selman and M. Husham: Sens. Bio-Sens. Res. 11 (2016) 8. https://doi.org/10.1016/j.sbsr.2016.09.003

29 C. Byrne, R. Fagan, S. Hinder, D. E. McCormack, and S. C. Pillai: RSC Adv. 6 (2016) 95232. https://doi. org/10.1039/c6ra19759k

30 J. S. Tobin, A. J. Turinske, N. Stojilovic, A. F. Lotus, and G. G. Chase: Curr. Appl Phys. 12 (2012) 919. https:// doi.org/10.1016/j.cap.2011.12.010

31 Q. Wang, Z. Qiao, P. Jiang, J. Kuang, W. Liu, and W. Cao: Solid State Sci. 77 (2018) 14. https://doi.org/10.1016/ j.solidstatesciences.2018.01.003

32 L. Shi and D. Weng: J. Environ. Sci. 20 (2008) 1263. https://doi.org/10.1016/S1001-0742(08)62219-6

33 W. Zhou, L. Gai, P. Hu, J. Cui, X. Liu, D. Wang, G. Li, H. Jiang, D. Liu, H. Liu, and J. Wang: CrystEngComm 13 (2011) 6643. https://doi.org/10.1039/c1ce05638g

34 J. Tiley, R. Srinivasan, R. Banerjee, G. B. Viswanathan, B. Toby, and H. L. Fraser: J. Mater. Sci. Technol. 25 (2009) 1369. https://doi.org/10.1179/174328409X399010

35 W. Li, C. Ni, H. Lin, C. P. Huang, and S. I. Shah: J. Appl. Phys. 96 (2004) 6663. https://doi. org/10.1063/1.1807520

36 R. A. Spurr and H. Myers: Anal. Chem. 29 (1957) 760. https://doi.org/10.1021/ac60125a006

37 N. Khatun, S. Tiwari, J. Lal, C. M. Tseng, S. W. Liu, S. Biring, and S. Sen: arXiv preprint arXiv.:1806.09159 (2018).

38 J. Choi, H. Park, and M. R. Hoffmann: J. Phys. Chem. C 114 (2009) 783. https://doi.org/10.1021/jp908088x

39 Y. H. Tseng, H. Y. Lin, C. S. Kuo, Y. Y. Li, and C. P. Huang: React. Kinet. Catal. Lett. 89 (2006) 69.

40 X. Chen and S. S. Mao: Chem. Rev. 107 (2007) 2891. https://doi.org/10.1021/cr0500535

41 Y. Zhang, C. X. Harris, P. Wallenmeyer, J. Murowchick, and X. Chen: J. Phys. Chem. C 117 (2013) 24015. https://doi.org/10.1021/jp406948e

42 M. M. Kamrannejad, A. Hasanzadeh, N. Nosoudi, L. Mai, and A. A. Babaluo: Mater. Res. 17 (2014) 1039. http://dx.doi.org/10.1590/1516-1439.267214

43 C. H. Hsieh, Y. J. Cheng, P. J. Li, C. H. Chen, M. Dubosc, R. M. Liang, and C. S. Hsu: J. Am. Chem. Soc. 132 (2010) 4887. https://doi.org/10.1021/ja100236b

44 M. H. Liao, C. H. Hsu, and D. H. Chen: J. Solid State Chem. 179 (2006) 2020. https://doi.org/10.1016/ j.jssc.2006.03.042

45 D. Jiang, Y. Xu, B. Hou, D. Wu, and Y. Sun: Eur. J. Inorg. Chem. 8 (2008) 1236. https://doi.org/10.1002/ ejic. 200700650

46 K. Sahbeni, I. Sta, M. Jlassi, M. Kandyla, M. Hajji, M. Kompitsas, and W. Dimassi: J. Phys. Chem. Biophys. 7 (2017) 2161. https://doi.org/10.4172/2161-0398.1000257

47 H. S. Ngo: Photocatalytic degradation of acetic acid in gas phase in the presence and in the absence of $\mathrm{O}_{2}$ using different $\mathrm{TiO}_{2}$ and $\mathrm{M}-\mathrm{TiO}_{2}$ : a comparative study on the conversion, mineralization and intermediates' selectivities (2017) (Doctoral dissertation, Université de Lyon) p. 88.

48 J. Wang, J. Yu, X. Zhu, and X. Z. Kong: Nanoscale Res. Lett. 7 (2012) 646. https://doi.org/10.1186/1556$276 \mathrm{X}-7-646$ 